\title{
Selection of Housekeeping Genes for Transgene Expression Analysis in Eucommia ulmoides Oliver Using Real-Time RT-PCR
}

\author{
Ren Chen, ${ }^{1}$ Mayumi Gyokusen, ${ }^{1}$ Yoshihisa Nakazawa, ${ }^{1}$ and Koichiro Gyokusen ${ }^{2}$ \\ ${ }^{1}$ Technical Research Institute, Hitachi Zosen Corporation, Osaka 551-0022, Japan \\ ${ }^{2}$ Department of Forest and Forest Products Sciences, Faculty of Agriculture, Kyushu University, Fukuoka 812-8581, Japan \\ Correspondence should be addressed to Ren Chen, chenren@agr.kyushu-u.ac.jp
}

Received 7 September 2009; Revised 19 December 2009; Accepted 19 January 2010

Academic Editor: Mee Len Chye

Copyright ( $) 2010$ Ren Chen et al. This is an open access article distributed under the Creative Commons Attribution License, which permits unrestricted use, distribution, and reproduction in any medium, provided the original work is properly cited.

\begin{abstract}
In order to select appropriate housekeeping genes for accurate calibration of experimental variations in real-time (RT-) PCR results in transgene expression analysis, particularly with respect to the influence of transgene on stability of endogenous housekeeping gene expression in transgenic plants, we outline a reliable strategy to identify the optimal housekeeping genes from a set of candidates by combining statistical analyses of their (RT-) PCR amplification efficiency, gene expression stability, and transgene influences. We used the strategy to select two genes, $A C T \alpha$ and $E F 1 \alpha$, from 10 candidate housekeeping genes, as the optimal housekeeping genes to evaluate transgenic Eucommia ulmoides Oliver root lines overexpressing IPPI or FPPS1 genes, which are involved in isoprenoid biosynthesis.
\end{abstract}

\section{Introduction}

Genetic transformation of plants is widely used to study plant physiology (biochemical pathways, resistance to pathogens, reaction to stresses) and to obtain commercial crops with improved agronomic characters (herbicide tolerance, insect resistance, etc.). More recently, it has also been used to develop new types of plants as bioreactors (pharmaceuticals, vaccines, nutraceuticals, etc.) [1]. Regardless of the transformation's purpose, when new transgenic plants are obtained, an early and essential step is to evaluate the transgene expression [1]. For many years the vast majority of gene expression studies have used nonquantitative or semiquantitative RNA gel blots and RT-PCR analysis [2]. Recent advances in PCR instrumentation and fluorescence chemistry have made the precise quantification of specific amplification products possible. Quantitative real-time (RT-) PCR technology quantifies products by detecting fluorescence emitted from specific double-stranded DNA binding dyes or fluorophore-labeled probes that hybridize with target sequences during the exponential phase of the PCR reaction [3]. However, this process can be affected by various experimental variations, including the amount of starting material, efficiencies of enzymes in the (RT-)
PCR reaction, and differences between tissues or cells in overall transcriptional activity. It is crucial, therefore, to amplify a housekeeping gene (also known as an "endogenous reference" gene) alongside the target gene to calibrate for experimental variability $[4,5]$. In these expression assays, the target concentration in each sample is calculated relative to the housekeeping gene and the result is expressed as the target/housekeeping ratio.

Many studies on housekeeping gene expression have dealt mainly with human tissues, bacteria, and viruses [6]. Only a few studies have focused on plants' vegetative and floral tissues, at different stages of development or under biotic or abiotic stress, for example, barley [7], rice [8], poplar [2], potato [6], Arabidopsis, and tobacco [9]. Except for a study which reported that NelF-4A is an ideal constitutively expressed control gene in the analysis of the transgenic tobacco expressing NelF-4A fused to the GUS reporter gene (the transgene expression of GUS matched the expression patterns of NelF-4A mRNA and protein) [10], there have been no reports on the evaluation of housekeeping genes for calibration of transgene expression, particularly with respect to the influence of transformation with the foreign gene on stability of endogenous housekeeping gene expression in transgenic plants. 
In this study, we chose 10 commonly used housekeeping genes and analyzed their expression levels in several transgenic root lines of Eucommia ulmoides Oliver using real-time RT-PCR. By combining statistical analyses of their (RT-) PCR amplification efficiency, expression stability, and transgene influences, we outlined a reliable strategy to select the optimal housekeeping genes for accurate calibration of real-time (RT-) PCR results in this E. ulmoides system.

E. ulmoides is a deciduous, dioecious woody plant, and is a Tertiary species that survives only in China [11]. It produces a trans-polyisoprene known as Eu-rubber in the leaves, root, bark, and pericarp [12, 13]. Eu-rubber has several specific properties that differ from those of natural rubber (cis-polyisoprene), including hard "plasticity." It is an excellent nonconductor and has an extremely low coefficient of thermal expansion/contraction that could be exploited in the manufacture of insulated cables, moulds, shoe soles, adhesives, medical or scientific appliances, and sports goods. Our ultimate goals were to isolate and characterize the genes related to Eu-rubber biosynthesis so that we can enhance or improve the quantity or quality of Eu-rubber products using gene transformation techniques. Genetic transformation and transgene expression analysis protocols developed in this study provide the basis for further genetic alteration of $E$. ulmoides.

\section{Materials and Methods}

2.1. Sample Preparation. A proliferated root line from a 4week-old germfree seedling of E. ulmoides by suspension culture was, respectively, infected with three lines of Agrobacterium tumefaciens LBA4404 [14], each harboring one of three types of binary vector, namely, pOEB1, pOEB5, or pOEB9 (Figure 1), all derived from pMSH1 [15]. The fulllength cDNAs of IPPI and FPPS1 (described in Results and Discussion) constructed in pOEB5 and pOEB9 were amplified by RT-PCR from E. ulmoides mRNA. After selection and differentiation, three transgenic root lines transformed with each type of Ti-plasmid were obtained. The nine transgenic root lines ( 3 transgenic types $\times 3$ lines) and the proliferated root line (wild-type, nontransformed negative control) were sampled in triplicate ( 3 transgenic types $\times 3$ lines $\times 3$ repeats +1 wild type $\times 1$ line $\times 3$ repeats $=30$ samples).

2.2. Total RNA Extraction. Total RNA was extracted from each sample using the RNeasy Plant Mini Kit (Qiagen) according to the manufacturer's instructions. To eliminate residual genomic DNA in the preparation, RNA samples were treated with the RNase-Free DNase I (Qiagen) and were tested by real-time PCR using $50 \mathrm{ng}$ RNA as template in the same conditions as described below. Then, the RNA was adjusted to $20 \mathrm{ng} / \mu \mathrm{L}$ (all sample qualities were assessed by $\mathrm{A}_{260 / 280}$ ratios, >1.9). Six diluting concentrations of RNA $(400,100,25,6.25,1.56,0.39 \mathrm{ng} / \mu \mathrm{L})$ were prepared and were used to construct a standard curve.

2.3. Primer Design. We selected 10 candidate housekeeping genes as follows: ACT $\alpha, A R P T, C Y P, E F 1 \alpha, E I F 1 \alpha, G A P D$, $r b c L, T U B \alpha, T U B \beta$, and UBQ. The IPPI and FPPS1 genes, which are involved in trans-polyisoprene (Eu-rubber) biosynthesis (described in Results and Discussion), were chosen as the target genes of interest. Primers were designed according to E. ulmoides EST sequences using Primer Express (Applied Biosystems) with melting temperatures of $59-60^{\circ} \mathrm{C}$. All primer pairs (Table 1) were initially tested by standard RT-PCR using the conditions described below for real-time RT-PCR. Amplification of single products of expected size was verified by electrophoresis on $3 \%$ agarose-LE (Nacalai Tesque).

2.4. Two-Step Real-Time RT-PCR. Sample cDNA (including the samples for standard curves) was synthesized from $10 \mu \mathrm{L}$ total RNA in a $20 \mu \mathrm{L}$ volume using the High Capacity Reverse Transcription Kit (Applied Biosystems). Real-time PCR was performed in a $25 \mu \mathrm{L}$ volume containing $150 \mathrm{nM}$ of each primer, $5 \mu \mathrm{L}$ cDNA sample $(\approx 10 \mathrm{ng} / \mu \mathrm{L})$ and $1 \times$ SYBR Green PCR Master Mix (Applied Biosystems) on the ABI Prism 7300 Sequence Detection System (Applied Biosystems). PCR reactions were carried out in a 96-well reaction plate using the parameters recommended by the manufacturer $\left(50^{\circ} \mathrm{C}\right.$ for 2 minutes, $95^{\circ} \mathrm{C}$ for 10 minutes, 40 cycles of $95^{\circ} \mathrm{C}$ for 15 seconds and $60^{\circ} \mathrm{C}$ for 1 minutes, and a dissociation stage of $95^{\circ} \mathrm{C}$ for 15 seconds, $60^{\circ} \mathrm{C}$ for 1 minutes, and $95^{\circ} \mathrm{C}$ for 15 seconds, $60^{\circ} \mathrm{C}$ for 15 seconds). Each PCR reaction was performed in triplicate and a no-template control was included.

2.5. Data Acquisition. The Ct value was defined as the cycle in which there is a significant increase in the amount of PCR product. Relative quantities were determined by interpolation from standard curves to create linear values for each sample. Both Ct value and relative quantity of each sample were acquired from the ABI Prism 7300 Sequence Detection System.

2.6. Statistical Analyses. The variability of absolute $\mathrm{Ct}$ value of each target (IPPI, FPPS1) and candidate housekeeping gene was calculated from all tested samples (total data number of each gene $=3$ transgenic types $\times 3$ lines $\times 3$ repeats +1 wild type $\times 1$ line $\times 3$ repeats $=30$ ). The PCR amplification efficiency of each target and candidate housekeeping gene was calculated from the slope of the standard curve (total data number of each gene $=6$ standard curve concentrations $\times 3$ repeats $=18$ ) according to the equation: PCR efficiency $=\left(10^{-1 / \text { slope }}-1\right) \times 100 \%$.

To validate the relatively equivalent of (RT-) PCR efficiencies between the target and the candidate housekeeping gene, the $\mathrm{Ct}$ values of a target gene and a candidate housekeeping gene from the samples for the standard curve were used (total data number of one gene pair (a target gene and a housekeeping gene) $=6$ standard curve concentrations $\times 3$ repeats $\times 2$ genes $=36$ ). The concentrations of the standard RNAs were transferred to $\log$ arithmic values $(\log 400, \log 100$, $\log 25, \log 6.25, \log 1.56, \log 0.39)$ and the $\Delta \mathrm{Ct}$ values (Ct target gene - Ct housekeeping gene of each sample) were plotted 
TABLE 1: Primers for real-time RT-PCR and their characteristics.

(a)

\begin{tabular}{lcc}
\hline Gene & Primer sequences (forward/reverse) & Length (bp) \\
\hline ACT $\alpha$ & TTGTTAGCAACTGGGATGATATGG/CAGGGTGTTCTTCAGGAGCAA & 84 \\
ARPT & GCTGTTCAAGCTGGAGAACGT/TTCCGCCAGTTGCAATGA & 58 \\
CYP & TGACTTCACCGCCGGAAA/GGCGAACTTGGCTCCATAGA & 58 \\
$E F 1 \alpha$ & CCGAGCGTGAACGTGGTAT/TAGTACTTGGTGGTTTCGAATTTCC & 64 \\
$E I F 1 \alpha$ & CCTCCGTATGCTTGGAAACG/TCTTGGTTCCGTCGATGCA & 56 \\
GAPD & GGCATTGTTGAGGGTCTTATGAC/TGGTCCATCAACAGTCTTCTGAGT & 69 \\
$r b c L$ & CGGTGTGGACCGATGGA/TGGTAGCACCGCCCTTTG & 55 \\
$T U B \alpha$ & TCAGGAAGCTTGCAGACAACTG/AACAGCGTGGAAAACCAGAAA & 59 \\
$T U B \beta$ & GGGCCAAAGGGCATTACACT/CGACATCGAGAACAGCATCAA & 57 \\
IPPQ & CCTGACCAGCAGAGGTTGATC/TCCGCCAGAGTCCTTCCAT & 62 \\
FPPS 1 & AACGATCAGGGACAAAGGTAACA/GGATGGCTGCAGCATGTG & 61 \\
\hline
\end{tabular}

(b)

\begin{tabular}{lccccccc}
\hline $\operatorname{Tm}\left({ }^{\circ} \mathrm{C}\right)$ & \multicolumn{5}{c}{ Ct value } & \multicolumn{3}{c}{ Standard curve } \\
& Average & SD & Range & CV $(\%)$ & Slope & $R^{2}$ & PCR efficiency $(\%)$ \\
\hline 76.5 & 22.738 & 1.192 & 5.489 & 5.243 & -3.330 & 0.927 & 99.67 \\
77.2 & 19.216 & 0.635 & 2.063 & 3.302 & -3.225 & 0.953 & 104.23 \\
79.1 & 28.035 & 0.750 & 3.696 & 2.673 & -2.981 & 0.932 & 116.50 \\
76.0 & 16.407 & 0.983 & 3.994 & 5.991 & -3.307 & 0.955 & 100.62 \\
79.3 & 19.232 & 1.040 & 3.971 & 5.408 & -3.143 & 0.941 & 108.04 \\
78.0 & 17.938 & 0.853 & 3.788 & 4.758 & -4.112 & 0.955 & 75.07 \\
79.0 & 13.330 & 0.905 & 3.347 & 6.792 & -2.991 & 0.941 & 115.95 \\
78.6 & 19.521 & 0.988 & 3.777 & 5.060 & -3.204 & 0.970 & 105.17 \\
77.0 & 21.242 & 1.426 & 4.973 & 6.714 & -2.847 & 0.901 & 124.50 \\
79.5 & 15.906 & 0.819 & 2.664 & 5.148 & -2.929 & 0.941 & 119.49 \\
79.3 & 23.070 & 1.740 & 5.706 & 7.541 & -3.409 & 0.966 & 96.48 \\
77.6 & 20.292 & 1.309 & 4.335 & 6.449 & -3.313 & 0.981 & 100.38 \\
\hline
\end{tabular}

Data are based on analyses of absolute Ct values from all tested samples and standard curve of each target (IPPI, FPPS1) and candidate housekeeping gene. Tm: melting temperature of real-time RT-PCR product; SD: standard deviation; Range: difference between the maximum and minimum Ct values; CV: coefficient of variation; Slope: slope of standard curve; $R^{2}$ : correlation coefficient of standard curve; PCR efficiency $=\left(10^{-1 / \text { slope }}-1\right) \times 100 \%$.
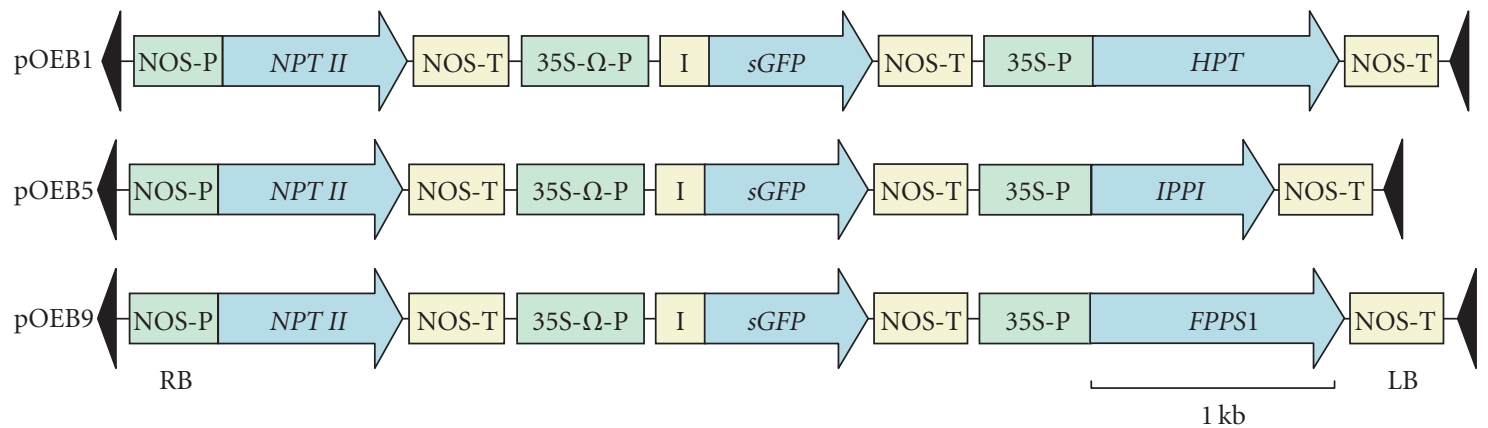

FIgure 1: Schematic structure of T-DNA regions of the binary vectors pOEB1, pOEB5, and pOEB9. RB: right border; LB: left border; I: intron of castor bean catalase gene CAT-1. 


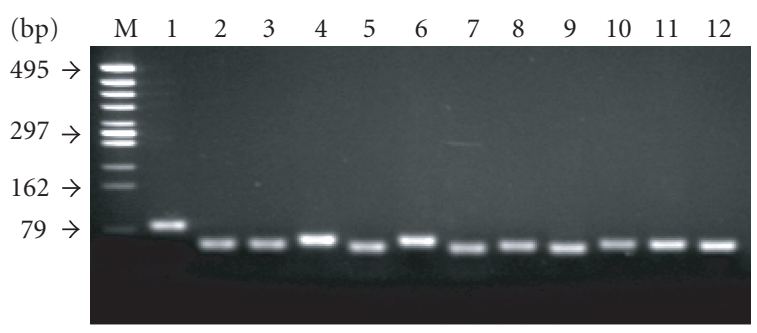

FIGURE 2: Validation of target and candidate housekeeping genes' PCR primer specificity by electrophoresis of the RT-PCR products on 3\% agarose gel. Lane M: DNA marker; Lane 1-12: ACT $\alpha, A R P T$, $C Y P, E F 1 \alpha, E I F 1 \alpha, G A P D, r b c L, T U B \alpha, T U B \beta, U B Q, I P P I$, and FPPS1.

versus log concentrations to create a semi-log regression line for calculating the line slope.

The stability of candidate housekeeping gene expression was evaluated using the geNorm method [16]. The relative quantities of all candidate housekeeping genes in all samples (total data number $=(3$ transgenic types $\times 3$ lines $\times 3$ repeats +1 wild type $\times 1$ line $\times 3$ repeats $) \times 10$ candidate housekeeping genes $=300$ ) were used to calculate $M$ and $V$ pairwise variation parameters (described in Results and Discussion).

Variance analysis of each candidate housekeeping gene expression was performed using variance components and mixed model ANOVA/ANCOVA (Statsoft). The relative quantities of each candidate housekeeping gene in the samples (total data number of each candidate housekeeping gene $=3$ transgenic types $\times 3$ lines $\times 3$ repeats +1 wild type $\times$ 1 line $\times 3$ repeats $=30$ ) were used to compare the variation of each candidate gene expression among the 4 transgenic types ( 3 transgenic types +1 wild type) and the variation among the transgenic lines within each transgenic type.

\section{Results and Discussion}

3.1. Evaluation of Target and Candidate Housekeeping Genes' PCR Primer Specificity and Variability of RNA Expression Level among All Tested Samples. By comparison to E. ulmoides EST sequences, primers were designed to be as specific as possible for the selected gene family member. All primer pairs were initially tested by standard RT-PCR using the same conditions as for real-time RT-PCR and by addition of a dissociation stage $\left(95^{\circ} \mathrm{C}\right.$ for 15 seconds, $60^{\circ} \mathrm{C}$ for 1 minute, and $95^{\circ} \mathrm{C}$ for 15 seconds, $60^{\circ} \mathrm{C}$ for 15 seconds) after real-time RT-PCR. The RT-PCR product of each gene verified by electrophoresis on 3\% agarose gel showed only a single band (Figure 2). Dissociation curve analysis also revealed that the real-time RT-PCR product of each gene had a unique melting peak (Tm, Table 1). The results indicated that each primer pair was specific and had no mismatch or false priming to the selected gene. Except GAPD (75.07\%) and TUB $\beta$ (124.50\%), all PCRs displayed amplification efficiency between $80 \%$ and $120 \%$ (Table 1 ).

To compare different RNA expression levels of target and candidate housekeeping genes over all tested samples,

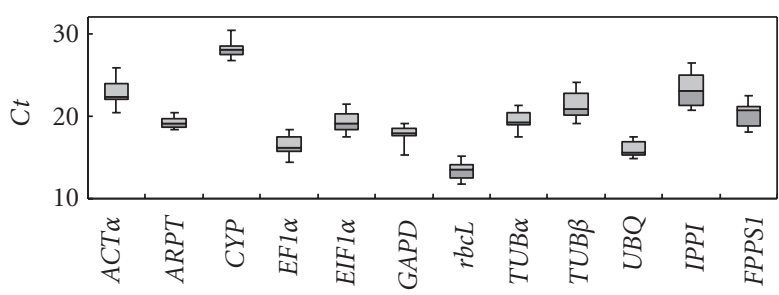

Target and candidate housekeeping gene

FIGURE 3: The variability of absolute Ct value in each target (IPPI, FPPS1) and candidate housekeeping gene among all tested samples. Grey bars indicate the 25/75 percentiles, whisker caps indicate the maximum and minimum, the line marks the median.

the variability of absolute $\mathrm{Ct}$ value was calculated. The results (Table 1, Figure 3 ) revealed that all genes presented the median $\mathrm{Ct}$ values between 15 and 25, excepted $r b c L$ (median $\mathrm{Ct}<15)$ and CYP (median $\mathrm{Ct}>25$ ). The lowest RNA expression range (the difference between the maximum and minimum $\mathrm{Ct}$ values) could be observed for the $A R P T$ followed by $U B Q$ and $r b c L$ (Table 1). The coefficient of variation $(\mathrm{CV})$ was $<10 \%$ for all target and candidate housekeeping genes (Table 1).

3.2. Validation of the Relatively Equivalent of (RT-) PCR Amplification Efficiencies between the Target and the Candidate Housekeeping Gene by Linear Regression Analyses. The target and candidate housekeeping genes' (RT-) PCR amplification efficiency is an important factor that affects quantification of target gene expression. To validate the relatively equivalent of (RT-) PCR amplification efficiencies between the target and the candidate housekeeping gene, the concentrations of standard RNAs transformed to logarithmic and the $\Delta \mathrm{Ct}$ values (Ct target gene - Ct housekeeping gene) were plotted to create a semilog regression line. If the target and the housekeeping genes' PCR amplification efficiency are equal, the slope of the semilog regression line will be approximately zero $(<0.1)$. As shown in Table 2 , only two housekeeping genes, $A C T \alpha$ and EF1 $\alpha$, had absolute values of the slope of $\Delta \mathrm{Ct}$ versus $\log$ concentrations $<0.1$, indicating that ACT $\alpha$ or EF1 $\alpha$ and the target genes IPPI or FPPS1 had similar or relatively equivalent (RT-) PCR efficiencies. In other words, using $A C T \alpha$ or EF1 $\alpha$ as housekeeping genes would calibrate the experimental variations in the IPPI or FPPS1 expression analyses more reliably. Another advantage of the housekeeping gene and the target gene having equivalent (RT-) PCR efficiencies is that we can calibrate experimental variations by the comparative $\mathrm{Ct}$ method (also known as the $\Delta \Delta \mathrm{Ct}$ method) without standard curves. This is particularly useful when only a few target genes are being studied, or when limited amounts of RNA are available.

3.3. Ranking of Candidate Housekeeping Genes with Respect to Expression Stability. Many studies have proposed that the optimal housekeeping gene to calibrate for experimental variation is one with the lowest variation in expression or one whose expression remains constant under different 
TABLE 2: Validation of the relatively equivalent of (RT-) PCR amplification efficiencies between the target and the candidate housekeeping gene.

\begin{tabular}{|c|c|c|c|c|c|c|c|c|c|c|}
\hline & $A C T \alpha$ & $A R P T$ & $C Y P$ & $E F 1 \alpha$ & $E I F 1 \alpha$ & GAPD & $r b c L$ & $T U B \alpha$ & $T U B \beta$ & $U B Q$ \\
\hline$I P P I$ & $-0.079^{*}$ & -0.185 & -0.448 & $-0.083^{*}$ & -0.266 & 0.702 & -0.418 & -0.205 & -0.562 & -0.480 \\
\hline FPPS1 & $0.017^{*}$ & -0.088 & -0.351 & $0.013^{*}$ & -0.169 & 0.772 & -0.322 & -0.109 & -0.465 & -0.384 \\
\hline
\end{tabular}

Data are based on linear regression analyses using $\Delta \mathrm{Ct}$ values (Ct target gene - Ct housekeeping gene) from the samples for standard curve versus log concentrations of standard curve; $*$ : slope of semilog regression line $<0.1$.

TABLE 3: ANOVA F-test of candidate housekeeping gene variances among three transgenic types and wild-type as well as among transgenic lines within each transgenic type.

\begin{tabular}{lcccccccccc}
\hline & $A C T \alpha$ & $A R P T$ & $C Y P$ & $E F 1 \alpha$ & $E I F 1 \alpha$ & GAPD & $r b c L$ & TUB $\alpha$ & TUB $\beta$ & UBQ \\
\hline Types & 3.99 & $5.30^{*}$ & 3.87 & 2.66 & $11.25^{* *}$ & 0.39 & $10.73^{* *}$ & $8.19^{*}$ & 4.57 & $93.55^{* *}$ \\
Lines & 1.55 & $8.70^{* *}$ & 2.47 & 2.26 & $8.06^{* *}$ & $5.43^{* *}$ & $7.20^{* *}$ & 1.63 & 2.07 & 0.46 \\
\hline
\end{tabular}

Data are based on variance components and mixed model ANOVA/ANCOVA using relative quantities of each candidate housekeeping gene in all samples; ${ }^{*}$, $P<.05 ; * *, P<.01$.

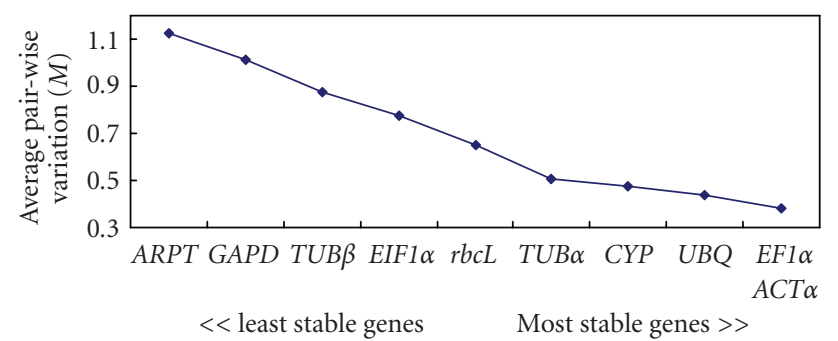

Figure 4: Average pairwise variation $(M)$ of candidate housekeeping genes plotted from least stable (left) to most stable (right).

experimental conditions. However, this can lead to incorrect interpretation of results, as often the gene with low variations in expression is low in abundance compared to target mRNA transcripts. Also, the use of $18 \mathrm{~S}$ or $28 \mathrm{~S}$ rRNA as housekeeping genes makes it difficult to accurately calibrate experimental variations as rRNA molecules are almost absent from purified mRNA samples, but make up the bulk of total RNA samples [16]. In practice, all genes will show some variation in expression under different conditions. Our analysis of absolute $\mathrm{Ct}$ value also revealed different variations over all target and candidate housekeeping genes (Table 1, Figure 3 ). In order to bypass this potential source of variation and more accurately evaluate the housekeeping gene expression stability, we decided to use the geNorm method. This method relies on the principle that the expression ratio of two perfect housekeeping genes would be identical in all samples in all experimental conditions. Variation in the expression ratios between different samples reflects the fact that one or both of the genes are not stably expressed. Vandesompele et al. [16] defined two parameters to quantify housekeeping gene stability: $M$ (the average pairwise variation of a particular gene compared with all other tested housekeeping genes; genes with the lowest $M$ values have the most stable expression) and $V$ (the pairwise variation $V_{n} / V_{n+1}$ between 2 sequential normalization factors, $\mathrm{NF}_{n}$ and $\mathrm{NF}_{n+1}$. A large $V$ value means that the added gene had a significant effect and should probably be included for calculation of the normalization factor). In

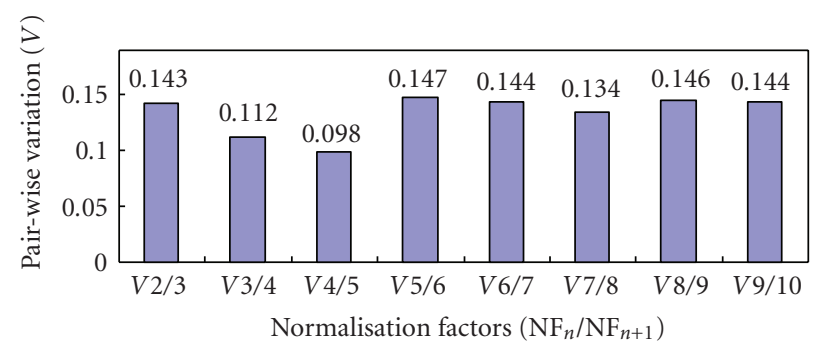

FIGURE 5: Pairwise variation $\left(V_{n} / V_{n+1}\right)$ between the normalization factors $\mathrm{NF}_{n}$ and $\mathrm{NF}_{n+1}$ to determine optimal number of housekeeping genes.

the present research, the relative quantities of all candidate housekeeping genes in all samples were used to calculate the two parameters. As shown in Figure 4, ACT $\alpha$ and EF1 $\alpha$ were the most stable genes with the lowest $M$ values. Since all the pairwise variations $V_{n} / V_{n+1}$ (Figure 5) were below the 0.15 cutoff value [16], an additional housekeeping gene did not contribute significantly to improving accuracy. Therefore, using the average of $A C T \alpha$ and EF1 $\alpha$ was sufficient for accurate calibration, and a third housekeeping gene $\left(V_{2 / 3}=\right.$ $0.143<0.15$ ) was not required as an internal control.

The geNorm analysis is independent of the difference in abundance between the genes and independent of variation among samples. It is equally affected by any outlying or extreme ratio (i.e., outliers for a sample with low or high overall expression, or outliers caused by an upregulated or downregulated gene that have an equivalent increase in pairwise variation, $V$ ) [16]. Therefore, the geNorm analysis has been used in several recent studies, as it is a robust method to evaluate stability of gene expression and to determine optimal housekeeping genes for calibration of the experimental variations $[4,5,17]$.

3.4. Examination of Transgene Influence on Housekeeping Gene Expression by ANOVA F-Test. In the pairwise comparison method (geNorm), special attention must be paid not to select housekeeping genes whose transcript expression can be influenced (or regulated) by the transgene in the transgenic plant, which theoretically should influence the 
relative target gene's expression (target/ housekeeping ratio) if the housekeeping gene and transgene are coregulated [18]. In the present research, we used variance components and mixed model ANOVA/ANCOVA analyses (Statsoft) to compare variations in expression levels of each housekeeping gene in different transgenic types and lines (Table 3 ). The results of ANOVA $F$-tests showed that four of the candidate housekeeping genes, ACT $\alpha, E F 1 \alpha$ (the two top-ranked candidates in the pairwise comparison approach), $C Y P$, and $T U B \beta$, had no significant variation in expression among the three transgenic types and the wild-type, as well as among the transgenic lines within each transgenic type $(P>.05)$. This result indicated that expression of these four genes was not influenced by gene transformation. In contrast, the other genes, ARPT, EIF1 $\alpha, G A P D, r b c L, T U B \alpha$, and $U B Q$, exhibited highly significant variations $(P<.05$ or .01$)$ in expression among the three transgenic types and the wildtype, indicating that the gene transformation had influenced their expression.

It is not surprising that overexpression of IPPI and FPPS1 in E. ulmoides will influence expression of some candidate housekeeping genes. In the plant isoprenoid biosynthesis pathway, IPPI catalyzes the interconversion of IPP to DMAPP, which is an essential starter moiety for the condensation reactions. IPP is sequentially condensed to DMAPP to yield the short-chain isoprenoid precursors GPP, FPP, and GGPP, which are further metabolized to monoterpenes (C10), sesquiterpenes (C15), diterpenes (C20), and polyisoprenes $(C>5000)[13,19]$. Plant isoprenoids are essential for numerous physiological and developmental processes in plants (photosynthesis, respiration, membrane fluidity, pathogen defense, and modulation of growth and stress responses via isoprenoid-derived plant hormones) [20]. Therefore, the changes of IPPI and FPPS1 expression levels in transgenic E. ulmoides are likely to influence other genes' expressions. In this case it may be prudent to examine the transgene influence on housekeeping gene expression rather than only ranking their expression stability by geNorm pairwise comparison approach.

In conclusion, we outline a reliable strategy to identify the optimal housekeeping genes for calibrating our realtime (RT-) PCR system by combining analyses of candidate housekeeping genes' (RT-) PCR amplification efficiency, expression stability, and transgene influences. We used the strategy to select $A C T \alpha$ and EF1 $\alpha$ as the optimal housekeeping genes in our analysis of transgene expression in transgenic E. ulmoides root lines overexpressing IPPI or FPPS1 genes, which are involved in isoprenoid biosynthesis. ACT is one of the major components of cytoplasmic microfilaments in eukaryotic cells. It plays an important role in diverse cellular functions, such as cytoplasmic streaming, changes in cytoarchitecture, and distribution of plasma membrane proteins in response to internal and external signals [21]. $\mathrm{EF} 1 \alpha$ is a ubiquitous protein that binds aminoacyl-transfer RNA to ribosomes during protein synthesis [22]. Both are housekeeping genes that are frequently used to calibrate target gene expression level $[6,23]$. This study provides a more reliable strategy to evaluate the appropriate housekeeping genes in transgene expression analysis.

\section{Abbreviations}

$\begin{array}{ll}\text { ACT } \alpha: & \text { Alpha actin } \\ \text { ARPT: } & \text { Adenine phosphoribosyl transferase } \\ \text { CYP: } & \text { Cyclophilin } \\ \text { EF1 } \alpha: & \text { Elongation factor-1 alpha } \\ \text { EIF1 } \alpha: & \text { Similarity to eukaryotic translation } \\ & \text { initiation factor alpha } \\ \text { GAPD: } & \text { Glyceraldehyde-3phosphate } \\ & \text { dehydrogenase } \\ \text { rbcL: } & \text { Ribulose 1,5-bisphosphate carboxylase } \\ \text { TUB } \alpha: & \text { Tubulin alpha-3 } \\ \text { TUB } \beta: & \text { Tubulin beta-9 chain } \\ \text { UBQ: } & \text { Polyubiquitin } \\ \text { IPP: } & \text { Isopentenyl diphosphate } \\ \text { IPPI: } & \text { IPP isomerase } \\ \text { FPP: } & \text { Farnesyl pyrophosphate } \\ \text { FPPS1: } & \text { FPP synthase } 1 \\ \text { DMAPP: } & \text { Dimethylallyl diphosphate } \\ \text { GPP: } & \text { Geranyl diphosphate } \\ \text { GGPP: } & \text { Geranylgeranyl pyrophosphate } \\ \text { GUS: } & \text { } 3 \text {-glucuronidase } \\ \text { sGFP (S65T): } & \text { Synthetic green-fluorescent protein } \\ & \text { with S65T mutation } \\ \text { NPT II: } & \text { Neomycin phosphotransferase II } \\ \text { HPT: } & \text { Hygromycin phosphotransferase } \\ \text { 35S-P: } & \text { Cauliflower mosaic virus (CaMV) 35S } \\ \text { 35S- } \Omega-P: & \text { promoter } \\ \text { NOS - P : } & \text { Nopromoter with an additional omega } \\ \text { NOS - T : } & \text { Nopaline synthase terminator } \\ \text { Ct: } & \text { Threshold cycle } \\ \text { ANCOVA: } & \text { Analysis of covariance. } \\ & \end{array}$

\section{Acknowledgment}

This work was supported by NEDO (New Energy and Industrial Technology Development Organization), Japan.

\section{References}

[1] G. Mason, P. Provero, A. M. Vaira, and G. P. Accotto, "Estimating the number of integrations in transformed plants by quantitative real-time PCR," BMC Biotechnology, vol. 2, article no. 20, 2002.

[2] A. M. Brunner, I. A. Yakovlev, and S. H. Strauss, "Validating internal controls for quantitative plant gene expression studies," BMC Plant Biology, vol. 4, article no. 14, 2004.

[3] P. Song, C. Q. Cai, M. Skokut, B. D. Kosegi, and J. F. Petolino, "Quantitative real-time PCR as a screening tool for estimating transgene copy number in WHISKERS-derived transgenic maize," Plant Cell Reports, vol. 20, no. 10, pp. 948-954, 2002.

[4] A. De Ketelaere, K. Goossens, L. Peelman, and C. Burvenich, "Technical note: validation of internal control genes for gene expression analysis in bovine polymorphonuclear leukocytes," Journal of Dairy Science, vol. 89, no. 10, pp. 4066-4069, 2006.

[5] T. Ishii, A. M. Wallace, X. Zhang, et al., "Stability of housekeeping genes in alveolar macrophages from COPD 
patients," European Respiratory Journal, vol. 27, no. 2, pp. 300 306, 2006.

[6] N. Nicot, J. F. Hausman, L. Hoffmann, and D. Evers, "Housekeeping gene selection for real-time RT-PCR normalization in potato during biotic and abiotic stress," Journal of Experimental Botany, vol. 56, no. 421, pp. 2907-2914, 2005.

[7] R. A. Burton, N. J. Shirley, B. J. King, A. J. Harvey, and G. B. Fincher, "The CesA gene family of barley. Quantitative analysis of transcripts reveals two groups of co-expressed genes," Plant Physiology, vol. 134, no. 1, pp. 224-236, 2004.

[8] B. R. Kim, H. Y. Nam, S. U. Kim, S. I. Kim, and Y. J. Chang, "Normalization of reverse transcription quantitativePCR with housekeeping genes in rice," Biotechnology Letters, vol. 25, no. 21, pp. 1869-1872, 2003.

[9] R. A. Volkov, I. I. Panchuk, and F. Schöffl, "Heat-stressdependency and developmental modulation of gene expression: the potential of house-keeping genes as internal standards in mRNA expression profiling using real-time RT-PCR," Journal of Experimental Botany, vol. 54, no. 391, pp. 2343 2349, 2003.

[10] T. Mandel, A. J. Fleming, R. Krähenbühl, and C. Kuhlemeier, "Definition of constitutive gene expression in plants: the translation initiation factor 4A gene as a model," Plant Molecular Biology, vol. 29, no. 5, pp. 995-1004, 1995.

[11] J. L. Wang, X. R. Liao, H. M. Zhang, J. F. Du, and P. L. Chen, "Accumulation of chlorogenic acid in cell suspension cultures of Eucommia ulmoides," Plant Cell, Tissue and Organ Culture, vol. 74, pp. 193-195, 2003.

[12] T. Bamba, E. Fukusaki, Y. Nakazawa, and A. Kobayashi, "Insitu chemical analyses of trans-polyisoprene by histochemical staining and Fourier transform infrared microspectroscopy in a rubber-producing plant, Eucommia ulmoides Oliver," Planta, vol. 215, pp. 934-939, 2002.

[13] J. Tangpakdee, Y. Tanaka, K. I. Shiba, S. Kawahara, K. Sakurai, and Y. Suzuki, "Structure and biosynthesis of transpolyisoprene from Eucommia ulmoides," Phytochemistry, vol. 45, no. 1, pp. 75-80, 1997.

[14] M. Bevan, "Binary Agrobacterium vectors for plant transformation," Nucleic Acids Research, vol. 12, no. 22, pp. 8711-8721, 1984.

[15] T. Kawasaki, K. Henmi, E. Ono, et al., “The small GTP-binding protein Rac is a regulator of cell death in plants," Proceedings of the National Academy of Sciences of the United States of America, vol. 96, no. 19, pp. 10922-10926, 1999.

[16] J. Vandesompele, K. De Preter, F. Pattyn, et al., "Accurate normalization of real-time quantitative RT-PCR data by geometric averaging of multiple internal control genes," Genome Biology, vol. 3, 2002.

[17] M. Kidd, B. Nadler, S. Mane, et al., "GeneChip, geNorm, and gastrointestinal tumors: novel reference genes for real-time PCR," Physiological Genomics, vol. 30, no. 3, pp. 363-370, 2007.

[18] C. L. Andersen, J. L. Jensen, and T. F. Ørntoft, "Normalization of real-time quantitative reverse transcription-PCR data: a model-based variance estimation approach to identify genes suited for normalization, applied to bladder and colon cancer data sets," Cancer Research, vol. 64, no. 15, pp. 5245-5250, 2004.

[19] K. Okada, H. Kasahara, S. Yamaguchi, et al., "Genetic evidence for the role of isopentenyl diphosphate isomerases in the mevalonate pathway and plant development in Arabidopsis," Plant and Cell Physiology, vol. 49, pp. 604-616, 2008.
[20] O. Laule, A. Fürholz, H. S. Chang, et al., "Crosstalk between cytosolic and plastidial pathways of isoprenoid biosynthesis in Arabidopsis thaliana," Proceedings of the National Academy of Sciences of the United States of America, vol. 100, no. 11, pp. 6866-6871, 2003.

[21] H. Ren, B. C. Gibbon, S. L. Ashworth, et al., "Actin purified from maize pollen functions in living plant cells," Plant Cell, vol. 9, no. 8, pp. 1445-1457, 1997.

[22] V. M. Ursin, J. M. Irvine, W. R. Hiatt, K. Christine, and C. K. Shewmaker, "Developmental analysis of elongation factor- $1 \alpha$ expression in transgenic tobacco," Plant Cell, vol. 3, no. 6, pp. 583-591, 1991.

[23] S. R. Stürzenbaum and P. Kille, "Control genes in quantitative molecular biological techniques: the variability of invariance," Comparative Biochemistry and Physiology B, vol. 130, no. 3, pp. 281-289, 2001. 

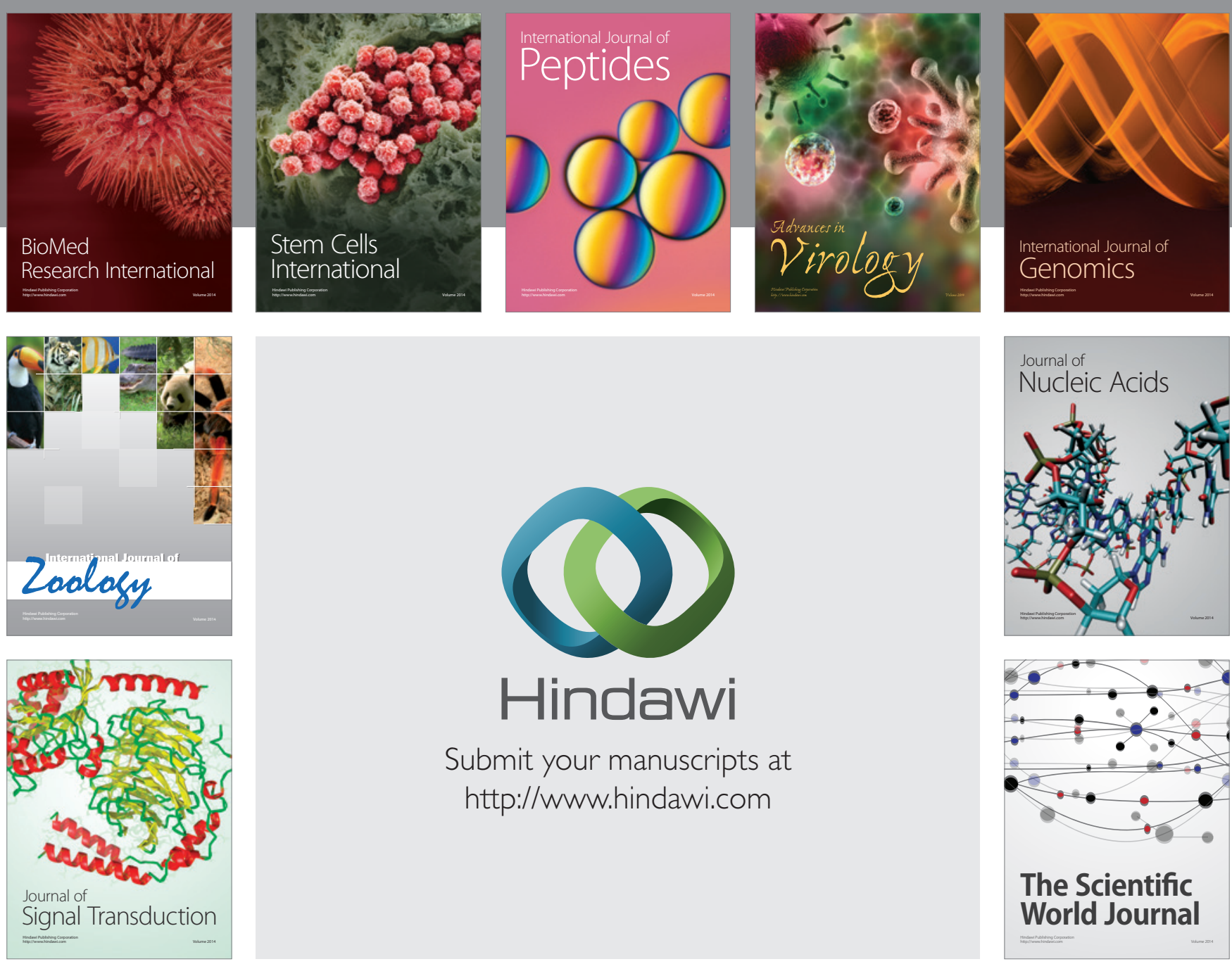

Submit your manuscripts at

http://www.hindawi.com
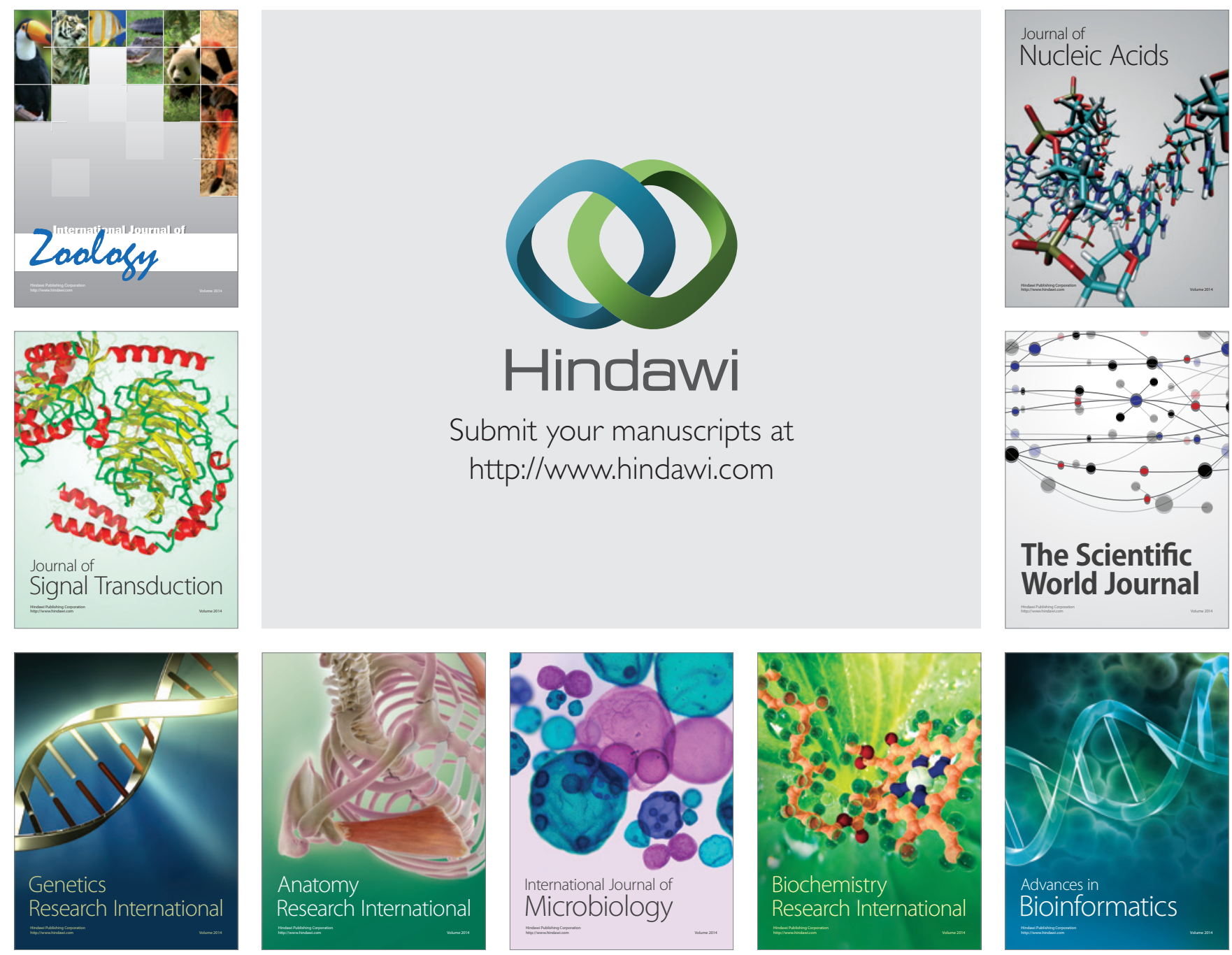

The Scientific World Journal
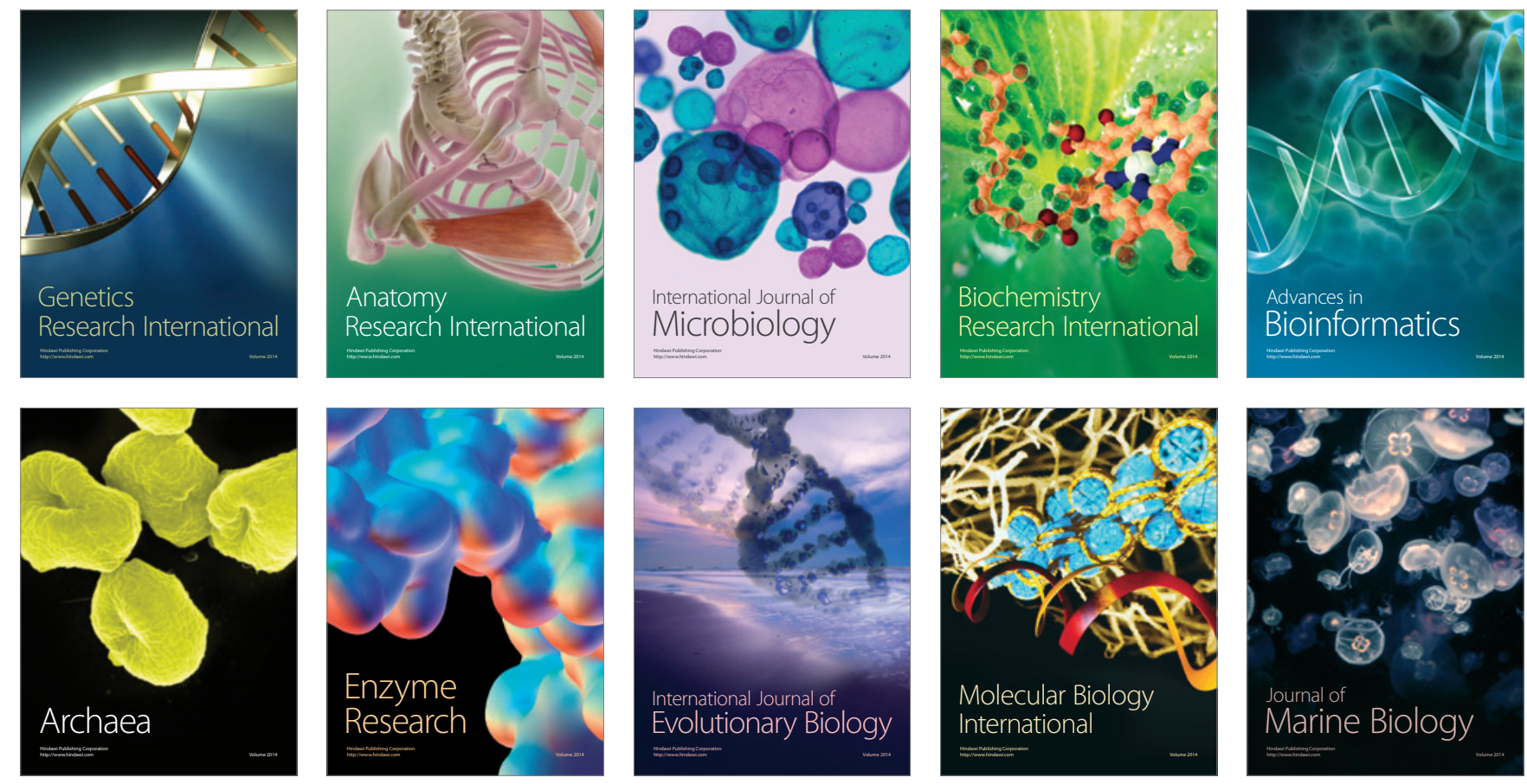